\title{
Effect of atorvastatin on inflammatory markers in hemodialysis patients
}

\author{
Hussein S. Hussein, Gamal E. Mady, Sahar M. Shawky, Noha A. Omran and Nahla M. Teama*
}

\begin{abstract}
Background: Cardiovascular disease is the commonest cause of death in patients with end-stage renal disease (ESRD) under maintenance hemodialysis. Dyslipidemia, oxidative stress, and low-grade inflammation with increased circulating cytokines are factors that increase the cardiovascular risk in patients with chronic kidney disease, in addition to traditional risk factors, such as obesity, hypertension, and diabetes. We aimed to investigate the possible anti-inflammatory effects of atorvastatin in prevalent hemodialysis patients. Fifty-three stable adult hemodialysis patients were assigned into two groups (a drug group and a control group). Patients in the drug group received $20 \mathrm{mg}$ of atorvastatin daily for 6 months. Serum levels of highly sensitive C-reactive protein (hs-CRP) and interleukin6 (IL-6) were measured in both groups at baseline and at the end of the study period.

Results: Atorvastatin therapy caused a statistically significant decrease in levels of hs-CRP but no change in levels of IL-6 after 6 months of therapy.

Conclusions: In addition to its favorable effect on lipid profile parameters, atorvastatin therapy can be considered as an effective and safe modality to overcome the problem of chronic inflammation encountered in end-stage renal disease patients.
\end{abstract}

Keywords: C-reactive protein, Interleukin-6, End-stage renal disease, Inflammation

\section{Background}

Cardiovascular disease is still considered the most common cause of mortality and morbidity in end-stage renal disease (ESRD) patients undergoing maintenance hemodialysis. Cardiovascular mortality in this patient population is about 30 times higher than the general population [1].

In addition to the traditional risk factors such as diabetes, hypertension, and obesity, the crucial role of inflammation in the pathogenesis of cardiovascular disease recently began to emerge, with several studies highlighting the ominous role of inflammatory mediators in this setting [2].

Statins, 3-hydroxy-3-methylglutaryl coenzyme A (HMG$\mathrm{CoA}$ ) reductase inhibitors, are used for the treatment of dyslipidemia. In addition to their lipid-lowering effects, they also have antioxidant, anti-inflammatory, and immunomodulatory effects, collectively known as "pleiotropic" effects [3].

\footnotetext{
* Correspondence: nahlateama@med.asu.edu.eg

Division of Nephroogy, Internal Medicine department, Ain Shams University

Faculty of Medicine, Cairo 11566, Egypt
}

These "pleiotropic" effects are achieved by inhibiting the synthesis of a variety of compounds, including isoprenoids derived from the mevalonate pathway which are involved in many important biological processes in all cell types [4].

The anti-inflammatory effects of statins and their favorable effects on cardiovascular risks have been well studied in the general population [5].

In this interventional randomized controlled trial, we evaluated the effects of atorvastatin treatment on the inflammatory markers (hs-CRP and IL-6) in prevalent hemodialysis patients.

\section{Methods \\ Fifty-three adult stable patients with ESRD on mainten- ance hemodialysis for at least 6 months were included in this study. Exclusion criteria included patients with a history of previous or current malignancy, recent sur- gery, genetic dyslipidemia, myopathies, or signs of active inflammation; smokers; and those taking corticosteroids,}

Springer Open

(c) The Author(s). 2020 Open Access This article is licensed under a Creative Commons Attribution 4.0 International License, which permits use, sharing, adaptation, distribution and reproduction in any medium or format, as long as you give appropriate credit to the original author(s) and the source, provide a link to the Creative Commons licence, and indicate if changes were made. The images or other third party material in this article are included in the article's Creative Commons licence, unless indicated otherwise in a credit line to the material. If material is not included in the article's Creative Commons licence and your intended use is not permitted by statutory regulation or exceeds the permitted use, you will need to obtain permission directly from the copyright holder. To view a copy of this licence, visit http://creativecommons.org/licenses/by/4.0/. 
antioxidants, and any hypolipidemic drugs for the preceding 2-3 months. Patients with three or more fold elevation of liver enzymes were also excluded. A detailed medical history was taken from each participant.

After eligibility was confirmed, patients were randomly assigned to one of the two groups. Randomization was done using sealed opaque envelops with random numbers. Each patient had an envelope once he/she agreed to participate in the study to be in one of the two groups:

- Group 1 (drug group) which included 33 patients who received oral atorvastatin $20 \mathrm{mg}$ daily [6] for a period of 6 months

- Group 2 (control group) which included 20 patients who did not receive atorvastatin

In all patients, hemodialysis was performed three times a week for $4 \mathrm{~h}$ on average, using the same dialyzer. A bicarbonate dialysis solution was used during hemodialysis sessions with an average flow rate of $300 \mathrm{ml} / \mathrm{h}$. All the selected patients had an adequate dialysis with urea reduction ratio $>65 \%$. Periodic follow-up visits were done for patients in their dialysis units.

A written informed consent was obtained from all patients participating in the study after explaining the benefits of the given therapy, its implications on their health, and the expected side effects.

\section{Measurements}

Citrate samples of venous blood were collected in the morning and in the fasting state before the mid-week session. The serum was separated, and samples were either analyzed immediately or kept frozen at $-80^{\circ} \mathrm{C}$ until the time of assay.

1. hs-CRP at baseline and after 6 months using a highsensitivity C-reactive protein ELISA Kit (ChemuxBioScience Inc., CA, USA)

2. IL- 6 at baseline and after 6 months using the Human Interleukin-6 ELISA Kit (Glory Science Co. Ltd., Del Rio, TX, USA)

3. Hemoglobin level

4. Lipid profile (total cholesterol, low-density lipoprotein cholesterol (LDL), high-density lipoprotein cholesterol (HDL), and serum triglyceride levels at baseline and after 6 months using standard kits)

5. Alanine transaminase (ALT), aspartate transaminase (AST), and total creatine kinase (CK-T) levels at baseline and at the end of the study period (after 6 months) using standard kits

\section{Sample size calculation}

After reviewing the literature [7], we used G*POWER statistical programming (version 3.1.9.4; Franz Faul,
University of Kiel, Germany) to calculate the sample size per group. Using $a=0.05$, a power of $85 \%$, an effect size of 0.835 , and an allocation ratio of $2: 1$ showed that a sample size of 60 (40 patients in the treatment group and 20 patients in the control group) was needed to avoid type II error. Seven patients were lost to follow-up from the drug group (2 underwent renal transplantation, 3 developed muscle pain with normal creatine kinase levels, 2 were non-compliant and asked to stop). So, there were 33 patients only in the drug group,

\section{Statistical analysis}

Data are presented as mean $\pm \mathrm{SD}$ or $N(\%)$. The baseline characteristics of patients randomized to the drug or control groups were compared by chi-square $\left(x^{2}\right.$ test) or independent samples $t$ test. Paired $t$ tests were used to compare values obtained at baseline and after 6 months. $P$ less than 0.05 is considered statistically significant, and $P$ less than 0.001 is considered highly statistically significant. The statistical analysis was performed using SPSS version 20.0 (SPSS Inc., Chicago, IL, USA).

\section{Results}

This study included 53 stable adult hemodialysis patients who were divided into two groups (Table 1):

1. Group 1 (drug group) which included 33 patients who received an oral daily dose of $20 \mathrm{mg}$ of atorvastatin for a period of 6 months

2. Group 2 (control group) which included 20 patients who did not receive atorvastatin

There was no statistically significant difference in age, sex, duration of hemodialysis therapy, and presence of diabetes, hypertension, or hepatitis $\mathrm{C}$ between the two groups (Fig. 1).

Overall, the underlying cause of renal failure was hypertension $(n=25)$, obstructive uropathy $(n=8)$, diabetic nephropathy $(n=6)$, unknown cause $(n=5)$, chronic glomerulonephritis $(n=3)$, interstitial nephritis $(n=3)$, lupus nephritis $(n=2)$, and autosomal dominant polycystic kidney disease $(n=1)$.

Baseline biochemical characteristics of the drug and control groups showed no statistically significant difference regarding levels of inflammatory markers (hs-CRP and IL-6), lipid profile parameters, and liver or muscle enzymes. The mean LDL in the atorvastatin group was $106.18 \pm 39.82 \mathrm{mg} / \mathrm{dl}$ prior to the treatment which means that some of these involved patients had baseline $\mathrm{LDL} \approx 65 \mathrm{mg} / \mathrm{dl}$; this was to detect the antiinflammatory effect in patients with dyslipidemia and patients without dyslipidemia (Table 2).

Atorvastatin therapy for 6 months caused a statistically significant decrease in levels of hs-CRP $(P<0.001)$. 
Table 1 Comparison between the drug and control groups as regards the demographic data of the enrolled patients at baseline

\begin{tabular}{|c|c|c|c|c|}
\hline & Drug group $(\boldsymbol{n}=33)$ & Control group $(\boldsymbol{n}=20)$ & Test & $\boldsymbol{P}$ value \\
\hline Age (years) & $52.03 \pm 11.36$ & $49.30 \pm 10.86$ & $t=0.743^{*}$ & 0.393 \\
\hline \multicolumn{5}{|l|}{ Gender } \\
\hline Male & $15(45.5 \%)$ & $11(55 \%)$ & $x^{2}=0.454^{* *}$ & 0.501 \\
\hline Female & $18(54.5 \%)$ & $9(45 \%)$ & & \\
\hline Duration of dialysis (years) & $7.29 \pm 5.69$ & $7.55 \pm 5.21$ & $t=0.028^{*}$ & 0.867 \\
\hline HCV-Ab positive & $10(30 \%)$ & $9(45 \%)$ & $x^{2}=1.170^{* *}$ & 0.279 \\
\hline Hypertension & $19(58 \%)$ & $13(65 \%)$ & $x^{2}=0.287^{* *}$ & 0.592 \\
\hline Diabetes mellitus & $4(12 \%)$ & $6(30 \%)$ & $x^{2}=2.600^{* *}$ & 0.107 \\
\hline
\end{tabular}

Data are mean \pm SD or $N(\%)$ for all variables

$H C V-A b$ hepatitis $C$ virus antibody

*Independent sample $t$ test

${ }^{* *}$ Chi-square test

However, there was no significant change in levels of IL6 at the end of the study period $(P=0.918)$. No change from baseline readings was demonstrable in the control group.

In the drug group, there was a statistically significant decrease in levels of total cholesterol $(P<0.001)$, LDL cholesterol $(P<0.001)$, and triglycerides $(P<0.001)$, in addition to a significant rise in levels of HDL cholesterol $(P=0.021)$ in response to atorvastatin therapy. No significant changes were observed in the control group.

Regarding the effect of atorvastatin therapy on liver and muscle enzymes, our results showed that there was no significant change in levels of liver transaminases as well as total creatine kinase after 6 months of atorvastatin therapy.

It shows a high statistically significant change in total cholesterol level $(P$ value $<0.001)$, LDL $(P$ value $<0.001)$, triglycerides $(P$ value $<0.001)$, and in hs-CRP $(P$ value $<$ $0.001)$ in the drug group after 6 months of atorvastatin therapy. There was a significant change in HDL ( $P$ value $<0.021)$ in the same group. Also, there was a significant change in LDL level $(P$ value $<0.051)$ in the control group. There was a statistically significant difference in total cholesterol level $(P$ value $<0.001)$, LDL ( $P$ value $<$ $0.001)$, triglycerides $(P$ value $<0.001)$, and in hs-CRP $(P$ value $<0.001)$ between the changes that occur in the

Patients Control

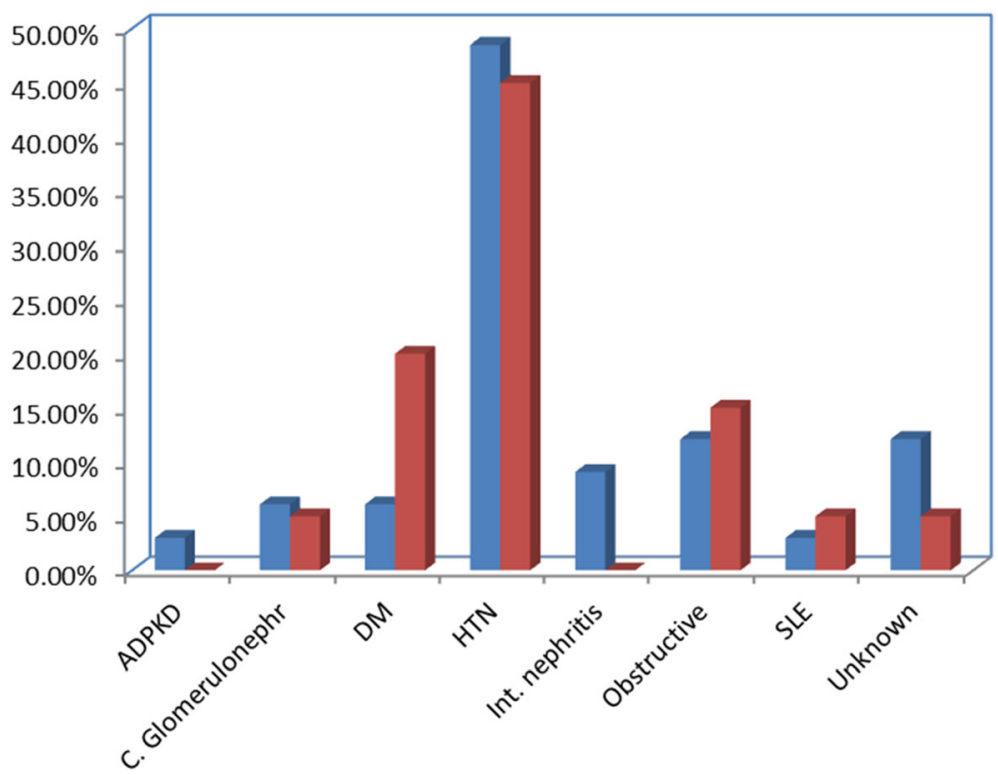

Fig. 1 Bar chart showing a comparison between the drug and control groups according to the etiology of renal failure 
Table 2 Comparison between the drug and control groups as regards the biochemical data at baseline and after 6 months

\begin{tabular}{|c|c|c|c|c|c|}
\hline & & \multicolumn{2}{|l|}{ Groups } & \multicolumn{2}{|l|}{$\boldsymbol{t}$ test } \\
\hline & & $\begin{array}{l}\text { Drug group, } \\
\text { mean } \pm S D\end{array}$ & $\begin{array}{l}\text { Control group, } \\
\text { mean } \pm \text { SD }\end{array}$ & $t$ & $\boldsymbol{P}$ value \\
\hline \multirow[t]{2}{*}{ AST } & Baseline & $17.879 \pm 6.348$ & $17.200 \pm 6.469$ & 0.375 & 0.709 \\
\hline & After 6 months & $15.242 \pm 5.831$ & $15.550 \pm 6.219$ & -0.182 & 0.857 \\
\hline \multirow[t]{2}{*}{ ALT } & Baseline & $15.727 \pm 6.458$ & $13.450 \pm 5.799$ & 1.292 & 0.202 \\
\hline & After 6 months & $14.061 \pm 4.115$ & $13.550 \pm 6.452$ & 0.352 & 0.726 \\
\hline \multirow[t]{2}{*}{ CK-T } & Baseline & $67.182 \pm 32.520$ & $71.350 \pm 33.039$ & -0.450 & 0.655 \\
\hline & After 6 months & $69.242 \pm 28.306$ & $81.900 \pm 33.176$ & -1.478 & 0.145 \\
\hline \multirow[t]{2}{*}{ T. cholesterol } & Baseline & $177.152 \pm 43.952$ & $164.650 \pm 56.611$ & 0.899 & 0.373 \\
\hline & After 6 months & $122.667 \pm 30.370$ & $175.800 \pm 60.845$ & -4.237 & $<0.001^{*}$ \\
\hline \multirow[t]{2}{*}{ HDL } & Baseline & $35.030 \pm 8.372$ & $37.050 \pm 9.827$ & -0.797 & 0.429 \\
\hline & After 6 months & $38.909 \pm 8.364$ & $37.150 \pm 10.205$ & 0.683 & 0.498 \\
\hline \multirow[t]{2}{*}{ LDL } & Baseline & $106.182 \pm 39.819$ & $93.200 \pm 43.397$ & 1.112 & 0.271 \\
\hline & After 6 months & $67.758 \pm 22.240$ & $110.000 \pm 47.703$ & -4.380 & $<0.001^{*}$ \\
\hline \multirow[t]{2}{*}{ Triglycerides } & Baseline & $179.939 \pm 65.941$ & $171.650 \pm 73.992$ & 0.424 & 0.674 \\
\hline & After 6 months & $97.879 \pm 39.478$ & $155.800 \pm 68.743$ & -3.906 & $<0.001^{*}$ \\
\hline \multirow[t]{2}{*}{ IL-6, pg/ml } & Baseline & $6.543 \pm 4.499$ & $6.800 \pm 4.295$ & -0.205 & 0.838 \\
\hline & After 6 months & $6.627 \pm 4.214$ & $7.085 \pm 3.575$ & -0.406 & 0.687 \\
\hline \multirow[t]{2}{*}{ CRP, mg/l } & Baseline & $8.989 \pm 5.223$ & $9.688 \pm 5.000$ & -0.480 & 0.634 \\
\hline & After 6 months & $4.850 \pm 4.058$ & $9.826 \pm 4.746$ & -4.058 & $<0.001^{*}$ \\
\hline
\end{tabular}

Data are mean \pm SD for all variables

hs-CRP highly sensitive C-reactive protein, IL-6 interleukin-6, LDL low-density lipoprotein, $H D L$ high-density lipoprotein, $A L T$ alanine transaminase, $A S T$ aspartate transaminase, $C K-T$ total creatine kinase

*Independent sample $t$ test

case and control groups from baseline to 6 months after atorvastatin therapy in the drug group (Tables 3, 4, 5, 6, and 7).

\section{Discussion}

Persistent low-grade inflammation appears to be an important contender in the pathogenesis of cardiovascular disease and the ensuing morbidity and mortality in prevalent hemodialysis patients [8]. In this study, we investigate the possible anti-inflammatory effects of atorvastatin in ESRD patients undergoing hemodialysis.

The results of our study revealed that atorvastatin therapy caused a statistically significant decrease in levels of hs-CRP after 6 months of therapy; however, it

Table 3 Comparison between the drug and control groups as regards the change in the biochemical data at baseline and after 6 months

\begin{tabular}{|c|c|c|c|c|c|}
\hline & Drug group, mean $\pm S D$ & Paired test, $\boldsymbol{P}$ value & Control group, mean \pm SD & Paired test, $\boldsymbol{P}$ value & $\boldsymbol{t}$ test, $\boldsymbol{P}$ value \\
\hline AST & $2.636 \pm 7.717$ & 0.058 & $1.650 \pm 6.507$ & 0.271 & 0.635 \\
\hline ALT & $1.667 \pm 6.406$ & 0.145 & $-0.100 \pm 8.169$ & 0.957 & 0.385 \\
\hline CK-T & $-2.061 \pm 28.402$ & 0.680 & $-10.550 \pm 42.960$ & 0.286 & 0.390 \\
\hline T. cholesterol & $54.485 \pm 46.438$ & $<0.001^{*}$ & $-11.150 \pm 40.547$ & 0.234 & $<0.001^{*}$ \\
\hline HDL & $-3.879 \pm 9.215$ & $0.021^{*}$ & $-0.100 \pm 6.617$ & 0.947 & 0.116 \\
\hline LDL & $38.424 \pm 41.218$ & $<0.001^{*}$ & $-16.800 \pm 36.071$ & $0.051^{*}$ & $<0.001^{*}$ \\
\hline Triglycerides & $82.061 \pm 53.615$ & $<0.001^{*}$ & $15.850 \pm 46.164$ & 0.141 & $<0.001^{*}$ \\
\hline IL-6, pg/ml & $-0.084 \pm 4.641$ & 0.918 & $-0.285 \pm 4.503$ & 0.780 & 0.878 \\
\hline hs-CRP, mg/l & $4.140 \pm 4.530$ & $<0.001^{*}$ & $-0.138 \pm 4.782$ & 0.899 & $0.002^{*}$ \\
\hline
\end{tabular}

Data are mean \pm SD for all variables

hs-CRP highly sensitive C-reactive protein, IL-6 interleukin-6, LDL low-density lipoprotein, $H D L$ high-density lipoprotein, $A L T$ alanine transaminase, $A S T$ aspartate transaminase, $C K-T$ total creatine kinase

*Paired sample $t$ test 
Table 4 Linear regression analysis displaying independent predictors of IL-6 at baseline

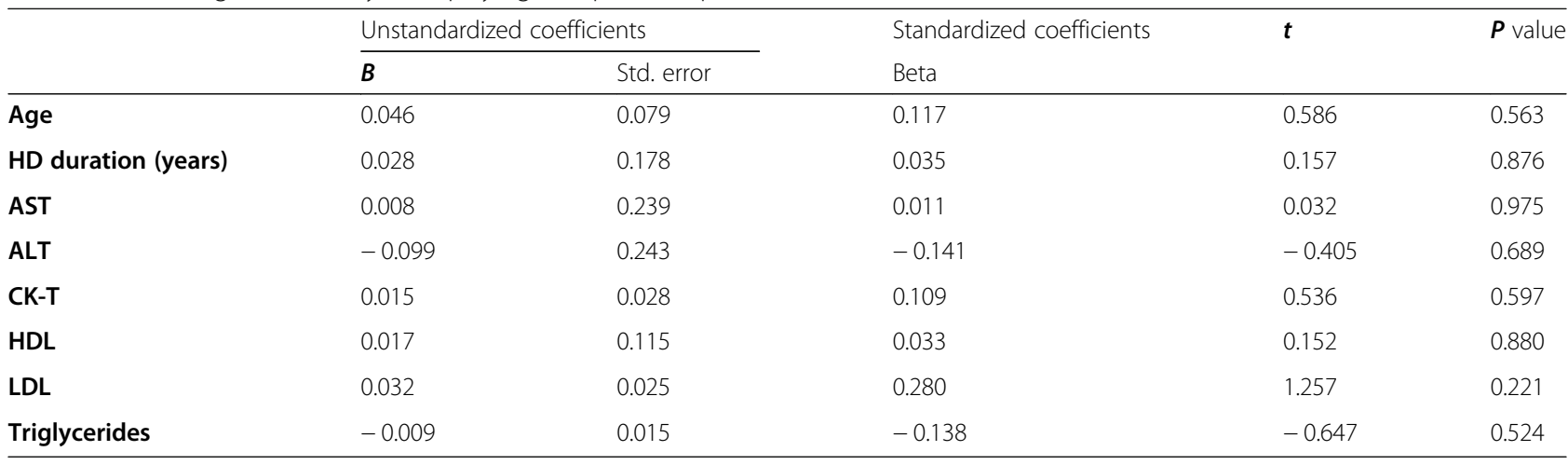

Dependent variable: IL-6, pg/ml, baseline

None of the studied variables is an independent predictor of IL- 6 level at baseline

IL-6 interleukin-6, LDL low-density lipoprotein, HDL high-density lipoprotein, $A L T$ alanine transaminase, AST aspartate transaminase, $C K-T$ total creatine kinase

failed to cause a significant change in levels of IL- 6 when compared to baseline levels.

The results published by Dornbrook-Lavender et al. [9] and Vernaglione et al. [10] come in line with our results. In both studies, $10 \mathrm{mg}$ of atorvastatin was administered to hemodialysis patients for 5 and 6 months, respectively. Despite the lower dose used, compared to our study, both studies showed a significant decrease in levels of hs-CRP. This decrease was statistically significant in the study by Vernaglione et al. [10], and sizeable but nonetheless insignificant in the study by Dornbrook-Lavender et al. [9].

Our results also agree to those by Tian et al. [11] where two groups of hemodialysis patients received either $20 \mathrm{mg}$ of atorvastatin or $10 \mathrm{mg}$ of rosuvastatin daily for 12 weeks. Both drugs significantly reduced the concentrations of hs-CRP; however, this effect was more pronounced in the atorvastatin group accompanied with improved nutritional status.

In the study by Kirmizis et al. [12], a daily dose of 10 mg of simvastatin for 6 months caused a significant decrease in levels of hs-CRP along with a significant decrease in levels of IL-6 in hemodialysis patients, which comes in partial agreement with our results.

A higher dose of simvastatin was evaluated in the studies by Chang et al. [7] and Shahbazian et al. [13]. In both trials, a daily dose of $20 \mathrm{mg}$ of simvastatin was given to a group of hemodialysis patients, for a period of 8 weeks and 12 weeks, respectively. In accordance with our results, in both studies, levels of hs-CRP showed a significant decrease at the end of the study period. However, Shahbazian et al. [13] also reported a significant decrease in levels of IL-6. These similarities in the effect on levels of hs-CRP come despite the shorter duration of statin administration in both studies compared to our study (8 weeks and 12 weeks versus 24 weeks in our study). This may suggest that the anti-inflammatory effect exerted by statins can be elicited both in the short and long terms.

The shortest recorded duration evaluated, as far as our knowledge goes, for the effect of a statin on levels of inflammatory makers comes from the study by Tsirpanlis

Table 5 Linear regression analysis displaying independent predictors of hs-CRP at baseline

\begin{tabular}{|c|c|c|c|c|c|}
\hline & \multicolumn{2}{|c|}{ Unstandardized coefficients } & \multirow{2}{*}{$\begin{array}{l}\text { Standardized coefficients } \\
\text { Beta }\end{array}$} & \multirow[t]{2}{*}{$t$} & \multirow[t]{2}{*}{$\boldsymbol{P}$ value } \\
\hline & $B$ & Std. error & & & \\
\hline Age & 0.131 & 0.083 & 0.286 & 1.583 & 0.127 \\
\hline Duration (years) & -0.154 & 0.187 & -0.168 & -0.822 & 0.419 \\
\hline AST & 0.344 & 0.252 & 0.418 & 1.364 & 0.185 \\
\hline ALT & -0.328 & 0.257 & -0.406 & -1.277 & 0.214 \\
\hline CK-T & 0.018 & 0.030 & 0.113 & 0.609 & 0.548 \\
\hline HDL & 0.068 & 0.121 & 0.109 & 0.561 & 0.580 \\
\hline LDL & 0.004 & 0.027 & 0.032 & 0.156 & 0.877 \\
\hline Triglycerides & 0.004 & 0.015 & 0.046 & 0.236 & 0.815 \\
\hline
\end{tabular}

Dependent variable: hs-CRP, mg/l, baseline

None of the studied variables is an independent predictor of hs-CRP level at baseline

hs-CRP highly sensitive C-reactive protein, $L D L$ low-density lipoprotein, HDL high-density lipoprotein, $A L T$ alanine transaminase, $A S T$ aspartate transaminase, $C K-T$ total creatine kinase 
Table 6 Linear regression analysis displaying independent predictors of IL-6 after 6 months

\begin{tabular}{|c|c|c|c|c|c|}
\hline & Unstand & & Standardized coefficients & $t$ & $\boldsymbol{P}$ value \\
\hline & $B$ & Std. error & Beta & & \\
\hline Age & -0.054 & 0.083 & -0.146 & -0.657 & 0.517 \\
\hline Duration (years) & 0.196 & 0.149 & 0.264 & 1.312 & 0.202 \\
\hline AST & 0.216 & 0.216 & 0.300 & 1.004 & 0.326 \\
\hline ALT & -0.433 & 0.295 & -0.423 & -1.468 & 0.156 \\
\hline CK-T & -0.005 & 0.030 & -0.033 & -0.161 & 0.873 \\
\hline T. cholesterol & 0.048 & 0.107 & 0.344 & 0.444 & 0.661 \\
\hline HDL & 0.131 & 0.153 & 0.259 & 0.856 & 0.401 \\
\hline LDL & -0.102 & 0.127 & -0.538 & -0.805 & 0.429 \\
\hline Triglycerides & -0.017 & 0.036 & -0.159 & -0.467 & 0.645 \\
\hline
\end{tabular}

Dependent variable: IL-6, pg/ml, after 6 months

None of the studied variables is an independent predictor of IL- 6 level after 6 months

IL-6 interleukin-6, LDL low-density lipoprotein, $H D L$ high-density lipoprotein, $A L T$ alanine transaminase, $A S T$ aspartate transaminase, $C K-T$ total creatine kinase

et al. [14], in which a daily dose of $40 \mathrm{mg}$ of fluvastatin was administered for a period of 4 weeks only. In complete disagreement with our results, levels of IL-6 decreased significantly at the end of the study period, while CRP levels did not change.

As regards the effect of atorvastatin on different parameters of lipid profile, our results revealed that the drug caused a statistically significant decrease in levels of total cholesterol, LDL cholesterol, and serum triglycerides with a significant increase in levels of HDL cholesterol.

These results agree fully with the results reported by Tsirpanlis et al. [14] and Tian et al. [11]. However, the latter reported that levels of LDL cholesterol decreased more significantly with improved nutrition status in the rosuvastatin group compared with the atorvastatin group.

Although the results by Kirmizis et al. [12] showed a significant decrease in levels of total cholesterol, LDL cholesterol, and triglycerides, HDL levels remained unchanged from their baseline values, which does not agree with our results.

Regarding the safety of atorvastatin therapy in hemodialysis patients who are considered to be a vulnerable subset of the population, our results revealed that transaminase levels as well as total creatine kinase levels failed to show any significant change in the drug group after intake of the drug for 6 months when compared to the control group.

This comes in agreement with the results by Tsirpanlis et al. [14], who demonstrated that there was no significant rise in the levels of AST and creatine kinase associated with fluvastatin therapy.

Also, in accordance with our results, Vernaglione et al. [10] and Shahbazian et al. [13] failed to record any significant elevations in hepatic or muscle enzymes that may be interpreted as side effects related to atorvastatin and simvastatin use, respectively.

Table 7 Linear regression analysis displaying independent predictors of hs-CRP after 6 months

\begin{tabular}{|c|c|c|c|c|c|}
\hline & \multicolumn{2}{|c|}{ Unstandardized coefficients } & \multirow{2}{*}{$\begin{array}{l}\text { Standardized coefficients } \\
\text { Beta }\end{array}$} & \multirow[t]{2}{*}{$t$} & \multirow[t]{2}{*}{$\boldsymbol{P}$ value } \\
\hline & $B$ & Std. error & & & \\
\hline Age & 0.052 & 0.070 & 0.146 & 0.741 & 0.466 \\
\hline HD duration (years) & -0.190 & 0.127 & -0.266 & -1.496 & 0.148 \\
\hline AST & -0.308 & 0.184 & -0.443 & -1.679 & 0.107 \\
\hline ALT & 0.346 & 0.251 & 0.351 & 1.378 & 0.181 \\
\hline CK-T & 0.059 & 0.026 & 0.452 & 2.303 & $0.031^{*}$ \\
\hline T. cholesterol & 0.036 & 0.091 & 0.270 & 0.395 & 0.697 \\
\hline HDL & -0.141 & 0.130 & -0.291 & -1.088 & 0.288 \\
\hline LDL & -0.049 & 0.108 & -0.269 & -0.456 & 0.653 \\
\hline Triglycerides & -0.045 & 0.031 & -0.437 & -1.453 & 0.160 \\
\hline
\end{tabular}

Dependent variable: CRP, $\mathrm{mg} / \mathrm{l}$, after 6 months

None of the studied variables is an independent predictor of hs-CRP level after 6 months except for CK-T $(P$ value $<0.031)$

hs-CRP highly sensitive C-reactive protein, $L D L$ low-density lipoprotein, $H D L$ high-density lipoprotein, $A L T$ alanine transaminase, $A S T$ aspartate transaminase, $C K-T$ total creatine kinase 
None of the patients in the drug group in the study by Shahbazian et al. [13] suffered any clinical side effects related to drug intake. In contrast, three patients who were originally allocated to the drug group in our study suffered from mild muscle pains nearly 1 month after starting atorvastatin therapy and chose to stop the drug, after which their symptoms readily improved. However, total creatine kinase levels performed for these patients at the time of complaint did not show any abnormalities. They were excluded from the statistical analysis.

Of special interest is the lack of correlation in our study between hs-CRP levels and total as well as LDL cholesterol levels after 6 months of atorvastatin therapy. This was also true for the results demonstrated by Vernaglione et al. [10], where hs-CRP levels did not correlate with levels of total cholesterol after 6 months of atorvastatin intake. Such scenarios suggest that the decrease in serum hs-CRP levels would be attributed to an effect of atorvastatin on hs-CRP, independent from the reduction in serum total or LDL cholesterol levels, entailing a different mechanism of action of statins on inflammatory markers.

This hypothesis is in disagreement with the results by Kirmizis et al. [12], which demonstrated a positive correlation between the decrease in levels of hs-CRP and the relative decrease in levels of total as well as LDL cholesterol, a finding that was not present in our study. However, in the same study, no similar correlation was found between changes in the lipid profile and IL-6 levels.

Linear regression analysis displaying independent predictors of IL-6 and hs-CRP at baseline and after 6 months showed that none of the studied variables is an independent predictor of IL- 6 and hs-CRP except for CK-T $(P$ value $<0.031)$ in hs-CRP level after 6 months.

The absence of a significant reduction in IL- 6 by atorvastatin could be related to its greater diurnal variability [15] and shorter half-life ( 2 to $4 \mathrm{~h}$ ) compared with CRP $(20 \mathrm{~h})$ [16]. Accordingly, it is likely that IL-6 was changing more rapidly than increasing its variance compared with CRP. Although the reductions in IL-6 with atorvastatin were not statistically significant, the trend observed for this marker agreed with the changes seen with CRP; this comes in agreement with Scott Kinlay et al. who studied the effect of high-dose atorvastatin (atorvastatin $80 \mathrm{mg} / \mathrm{d}$ ) on the decline in inflammatory markers in patients with acute coronary syndromes in the MIRACL Study [17].

\section{Conclusion}

Atorvastatin therapy can be considered as an effective and safe modality to overcome the problem of chronic inflammation encountered in end-stage renal disease patients on maintenance hemodialysis. This is reflected by its effect on reducing levels of hs-CRP, evident after 6 months of therapy, in addition to its favorable effect on lipid profile parameters in this patient population.

\section{Abbreviations}

HCV: Hepatitis C virus; ALT: Alanine aminotransferase; AST: Aspartate aminotransferase; ESRD: End-stage renal disease; SPSS: Statistical Package for Social Sciences; Hb: Hemoglobin; hs-CRP: Highly sensitive C-reactive protein; IL-6: Interleukin-6; LDL: Low-density lipoprotein; HDL: High-density lipoprotein; CK-T: Total creatine kinase; HMG-CoA: 3-Hydroxy-3-methylglutaryl coenzyme A; ELISA: Enzyme-linked immunosorbent assay; MIRA

CL: Myocardial Ischemia Reduction with Aggressive Cholesterol Lowering

\section{Acknowledgements}

Not applicable

\section{Authors' contributions}

NOA and NMT analyzed and interpreted the patient data. GEM, HSH, and SMS put the study design. NMT was a major contributor in writing the manuscript. All authors read and approved the final manuscript.

\section{Funding}

The authors declare that they have no funding sources.

\section{Availability of data and materials}

All data generated or analyzed during this study are included in this published article [and its supplementary information files].

\section{Ethics approval and consent to participate}

This study was performed in accordance with the ethical standards of the Ain Shams University Research Committee (committees reference number 340/2015) and with the 1964 Helsinki Declaration and its later amendments or comparable ethical standards.

A written informed consent was obtained from all individual participants included in the study.

\section{Consent for publication \\ Not applicable}

\section{Competing interests}

The authors declare that they have no competing interests.

Received: 18 May 2020 Accepted: 29 June 2020

Published online: 22 September 2020

\section{References}

1. Tonelli M, Wiebe N, Culleton B, House A, Rabbat C, Fok M et al (2006 Jul 1) Chronic kidney disease and mortality risk: a systematic review. J Am Soc Nephrol. 17(7):2034-2047

2. Carnevale D, Cifelli G, Mascio G, Madonna M, Sbroggiò M, Perrino C et al (2011Sep) Placental growth factor regulates cardiac inflammation through the tissue inhibitor of metalloproteinases-3/tumor necrosis factor-aconverting enzyme axis: crucial role for adaptive cardiac remodeling during cardiac pressure overload. Circulation 124(12):1337-1350

3. Liao JK, Laufs U (2005) Pleiotropic effects of statins. Annu Rev PharmacolToxicol 10(45):89-118

4. Buhaescu I, Izzedine H (2007Jun 1) Mevalonate pathway: a review of clinical and therapeutical implications. Clin Biochem 40(9-10):575-584

5. Tsimihodimos V, Mitrogianni Z, Ekisaf M (2011) Dyslipidemia associated with chronic kidney disease. The Open Cardiovascular Medicine Journal. 5:41-48

6. Wanner C, Tonelli M (2014 Jun 1) KDIGO Clinical Practice Guideline for Lipid Management in CKD: summary of recommendation statements and clinical approach to the patient. Kidney International. 85(6):1303-1309

7. Chang JW, Yang WS, Min WK, Lee SK, Park JS, Kim SB (2002) Effects of simvastatin on high-sensitivity C-reactive protein and serum albumin in hemodialysis patients. Am J Kidney Dis. 39(6):1213-1217.

8. Stenvinkel P, Carrero JJ, Axelsson J, Lindholm B, Heimbürger O, Massy Z (2008 Mar 1) Emerging biomarkers for evaluating cardiovascular risk in the chronic kidney disease patient: how do new pieces fit into the uremic puzzle? Clin J Am Soc Nephrol. 3(2):505-521

9. Dornbrook-Lavender KA, Joy MS, Denu-Ciocca CJ, Chin H, Hogan SL, Pieper JA (2005;Mar) Effects of atorvastatin on low-density lipoprotein cholesterol phenotype and C-reactive protein levels in patients undergoing long-term dialysis. Pharmacotherapy: The Journal of Human Pharmacology and Drug Therapy 25(3):335-344 
10. Vernaglione L, Cristofano C, Muscogiuri P, Chimienti S (2004;Mar 1) Does atorvastatin influence serum C-reactive protein levels in patients on longterm hemodialysis? Am J Kidney Dis 43(3):471-478

11. Tian J, Hou X, Hu L, Chen T, Wu K, Cai C et al (2017Jan 1) Efficacy comparison of atorvastatin versus rosuvastatin on blood lipid and microinflammatory state in maintenance hemodialysis patients. Ren Fail 39(1):153-158

12. Kirmizis D, Papagianni A, Dogrammatzi F, Skoura L, Belechri AM, Alexopoulos E et al (2010) Effects of simvastatin on markers of inflammation, oxidative stress and endothelial cell apoptosis in patients on chronic hemodialysis. J AtherosclerThromb. 17(12):1256-1265

13. Shahbazian H, Atrian A, Yazdanpanah L, Lashkarara GR, Mohtashami AZ (2015) Anti-inflammatory effect of simvastatin in hemodialysis patients, Jundishapur Journal of Natural Pharmaceutical Products 10(1)

14. Tsirpanlis G, Boufidou F, Manganas S, Chantzis K, Bleta A, Stamatelou K et al (2004) Treatment with fluvastatin rapidly modulates, via different pathways, and in dependence on the baseline level, inflammation in hemodialysis patients. Blood Purif. 22(6):518-524

15. Meier-Ewert HK, Ridker PM, Rifai N et al (2001) Absence of diurnal variation of C-reactive protein concentrations in healthy human subjects. Clin Chem. 47:426-430

16. Liuzzo G, Biasucci LM, Gallimore JR, Caligiuri G, Rebuzzi AG, Pepys MB et al (1999) Enhanced inflammatory response in patients with preinfarction unstable angina. J Am Coll Cardiol. 34(6):1696-1703

17. Kinlay S, Schwartz GG, Olsson AG, Rifai N, Leslie SJ, Sasiela WJ et al (2003) High-dose atorvastatin enhances the decline in inflammatory markers in patients with acute coronary syndromes in the MIRACL Study. Circulation. 108(13):1560-1566

\section{Publisher's Note}

Springer Nature remains neutral with regard to jurisdictional claims in published maps and institutional affiliations.

\section{Submit your manuscript to a SpringerOpen ${ }^{\circ}$ journal and benefit from:}

- Convenient online submission

- Rigorous peer review

- Open access: articles freely available online

High visibility within the field

- Retaining the copyright to your article

Submit your next manuscript at $\boldsymbol{\nabla}$ springeropen.com 